\title{
Protein and lipid MALDI profiles classify breast cancers according to the intrinsic subtype
}

\author{
Han Sung Kang ${ }^{1 \dagger}$, Seok Cheol Lee ${ }^{1,5 \dagger}$, Young Seung Park ${ }^{2}$, Young Eun Jeon ${ }^{3}$, Jeong Hwa Lee ${ }^{4}$, So-Youn Jung ${ }^{1}$, \\ In Hae Park', Seok Hoon Jang ${ }^{1}$, Hye Min Park', Chong Woo Yoo ${ }^{1}$, Seok Hee Park ${ }^{5}$, Sang Yun Han ${ }^{3}$, \\ Kwang Pyo Kim ${ }^{4}$, Young Hwan Kim²,6, Jungsil Ro ${ }^{1 *}$ and Hark Kyun Kim ${ }^{1 *}$
}

\begin{abstract}
Background: Matrix-assisted laser desorption/ionization (MALDI) mass spectrometry (MS) has been demonstrated to be useful for molecular profiling of common solid tumors. Using recently developed MALDI matrices for lipid profiling, we evaluated whether direct tissue MALDI MS analysis on proteins and lipids may classify human breast cancer samples according to the intrinsic subtype.

Methods: Thirty-four pairs of frozen, resected breast cancer and adjacent normal tissue samples were analyzed using histology-directed, MALDI MS analysis. Sinapinic acid and 2,5-dihydroxybenzoic acid/ $\alpha$-cyano-4hydroxycinnamic acid were manually deposited on areas of each tissue section enriched in epithelial cells to identify lipid profiles, and mass spectra were acquired using a MALDI-time of flight instrument.

Results: Protein and lipid profiles distinguish cancer from adjacent normal tissue samples with the median prediction accuracy of $94.1 \%$. Luminal, HER2+, and triple-negative tumors demonstrated different protein and lipid profiles, as evidenced by permutation $P$ values less than 0.01 for $0.632+$ bootstrap cross-validated misclassification rates with all classifiers tested. Discriminatory proteins and lipids were useful for classifying tumors according to the intrinsic subtype with median prediction accuracies of $80.0-81.3 \%$ in random test sets.
\end{abstract}

Conclusions: Protein and lipid profiles accurately distinguish tumor from adjacent normal tissue and classify breast cancers according to the intrinsic subtype.

Keywords: protein, lipid, breast cancer, MALDI

\section{Background}

Proteomics research is actively being performed to find biomarkers for common solid tumors [1,2] including breast cancer [3-5]. Matrix-assisted laser desorption/ ionization (MALDI) mass spectrometry (MS) has been demonstrated to be useful for histological classification [6-10] and outcome prediction [11] of common solid tumors.

In this approach, thin sections of frozen tissues are obtained from surgical resections or biopsies and mass spectra are obtained from discrete locations on the tissue. In a study of human breast cancer samples, protein profiles obtained from histology-directed MALDI MS

\footnotetext{
* Correspondence: jungsro@ncc.re.kr; hkim@ncc.re.kr

† Contributed equally

${ }^{1}$ National Cancer Center, Goyang, 410-769, Korea

Full list of author information is available at the end of the article
}

differentiate invasive breast cancers from ductal carcinoma in situ and normal breast epithelium [12]. In another report, MALDI imaging MS classified breast cancer tissue specimens according to HER2 status [13].

Accumulating evidence suggests that alteration in lipid composition is associated with breast carcinogenesis [14-16]. Recently, cancer-associated lipid alteration was extensively characterized using ultra performance liquid chromatography-MS analysis of tissue lysate from breast cancer tissue specimens [16]. These reports suggest that monitoring lipid composition in clinical samples may provide an opportunity for breast cancer diagnosis.

Breast cancer is the second most commonly diagnosed cancer in women worldwide [17]. Recent advances in the development of matrices for MALDI MS made it possible to directly probe tissues to profile lipid composition and distribution $[18,19]$. Using frozen surgical breast cancer 
tissue samples, we performed a comprehensive, histology-directed MALDI MS analysis of protein and lipid to evaluate whether this approach can differentiate and classify breast cancers. Here we demonstrate that protein and lipid MALDI MS profiles accurately differentiate breast cancers from normal epithelium, and classify breast tumors according to their intrinsic subtype.

\section{Methods}

\section{Collecting and processing clinical material and protein MALDI MS analysis}

Thirty-four pairs of breast cancer and adjacent normal tissue samples were collected at the time of surgery, with informed consent and institutional review board approval, from breast cancer patients undergoing surgery at National Cancer Center in Korea from 2001 to 2010, and stored in liquid nitrogen until analysis. Eleven samples were excluded by spectra quality filter of ClinProTools (version 2.2, Bruker Daltonics). Additional 21 samples were excluded because of inadequate $(<50 \%)$ tumor content. These excluded samples were not different from samples analyzed in this study in patient age or intrinsic subtype. Breast cancer intrinsic subtypes were classified according to an immunohistochemistry (IHC) surrogate panel $[20,21]$ as follows: luminal [estrogen receptor (ER) positive and/or progesterone receptor (PR) positive], HER2+ [HER2 + regardless of hormone receptor status], and triple-negative [ER-, PR-, and HER2-]. A cut-off value of $1 \%$ or more of positively stained nuclei was used to define ER and PR positivity. HER2 was scored as 0-3+ according to the method recommended for the HercepTest (Dako, Glostrup, Denmark). The cases with IHC scores of 3+ or ERBB2 gene amplification by fluorescence in situ hybridization (FISH) were considered positive for HER2.

Thin $(10 \mu \mathrm{m})$ sections were obtained from the frozen tissues using a cryostat (Leica CM 3050S, Leica Microsystems Inc., Bannockburn, IL). Multiple (three to seven) serial sections were obtained from each tissue. One section was affixed to a standard glass slide, and then stained with hematoxylin and eosin (H\&E). The other sections were thaw-mounted onto an indium tin oxide (ITO) slide (HST Inc., Newark, NJ), desiccated in vacuum for 20 min, and washed with graded ethanol solutions (70\%, $90 \%$, and $95 \%$ ethanol for 30 sec each) for subsequent protein MALDI MS analysis. Sinapinic acid (SA) was used as the protein MALDI matrix and prepared as a 20 $\mathrm{mg} / \mathrm{ml}$ solution in $50: 50$ acetonitrile: $0.1 \%$ trifluoroacetic acid (TFA). Using a micropipette, $250 \mathrm{nl}$ of the matrix was manually deposited twice per spot. The H\&E-stained serial section was then evaluated by a pathologist, who confirmed that entire H\&E section of tumor samples had at least $50 \%$ tumor content. Mass spectra were acquired using an Autoflex III (Bruker Daltonics, Bremen, Germany) MALDI TOF equipped with a SmartBeam laser (Nd:YAG, $355 \mathrm{~nm}$ ) and run using a linear-mode acquisition method optimized for $2-30 \mathrm{kDa}$, a laser frequency of $200 \mathrm{~Hz}$, and a delay time of $7 \mathrm{~ns}$. A total of 400 spectra were acquired at each spot position.

\section{Lipid MALDI MS analysis}

For lipid MALDI MS analysis, the binary matrix solution was prepared by dissolving $7 \mathrm{mg}$ each of 2, 5-dihydroxybenzoic acid (DHB) and $\alpha$-cyano-4-hydroxycinnamic acid (CHCA) in $1 \mathrm{~mL}$ of $70 \%$ methanol plus $0.1 \%$ TFA and $1 \%$ piperidine [19]. Under the guidance of the same H\&Estained adjacent section, the binary matrix $(250 \mathrm{nl} \times 2)$ was manually deposited on the tumor-rich area of cryosections that were thaw-mounted onto ITO slides. Mass spectra were acquired both in positive- and negative-ion reflector modes, using an Autoflex III (Bruker Daltonics) TOF equipped with a SmartBeam laser and run using a linear-mode acquisition method optimized for 500-1,200 $\mathrm{Da}$, a laser frequency of $200 \mathrm{~Hz}$ (3,000 consecutive laser shots), and a delay time of $0 \mathrm{~ns}$. Before each data acquisition, an external calibration was conducted using lipidmixed calibration standards with $\mathrm{m} / \mathrm{z}$ ranges of $674-834$ $\mathrm{Da}$ (positive ion mode) and 564-906 Da (negative ion mode).

MALDI LIFT (MS/MS) analysis was directly performed on the tissue section after MALDI MS. LIFT data and some lipid databases http://lipidsearch.jp or http://www. lipidmaps.org were used to facilitate and confirm the assignment of phospholipid species.

\section{Data Processing and Statistical Analysis}

ClinProTools was used for baseline subtraction, spectral recalibration, and spectral area calculation. A resolution of 300 was applied to the peak detection method. The Top Hat baseline with $10 \%$ minimal baseline width was used for baseline subtraction. Data reduction was performed at a factor of four. Spectra were recalibrated with a maximal peak shift of 2,000 ppm between reference and peak masses. The value of the "\% Match to Calibrant Peaks" parameter was set to $20 \%$. Spectra that were not recalibratable were excluded. All data with signal-to-noise ratios > 5 were acquired, and the peak area was used for peak calculation with zero level integration. An average peak list was set up for each tissue sample by choosing peaks on the calculated total average spectrum for each tissue sample to create one average spectrum per patient. Peaks with the highest intensity in each ion mode $(\mathrm{m} / \mathrm{z}=616.23$ and 539.53 in positive and negative ion modes respectively) were identified as non-lipid molecules and therefore excluded from subsequent analysis. Average-normalized datasets (i.e., protein, positive mode-lipid, and negativemode lipid datasets) were then combined into a single dataset and subjected to statistical analysis using BRBArrayTools (NCI, version 3.8) [22]. A principal component 
analysis (PCA) plot was generated using multi-dimensional scaling analysis of BRB-ArrayTools, which graphically represents correlation coefficients among samples without forcing the samples into specific clusters. The three primary principal components were used as the axes for the 3-dimensional scaling representation. Class comparison and class prediction analyses were also performed using BRB-ArrayTools. The class comparison analysis computed the F-test for each peak, and listed peaks differentially expressed among the classes at selected statistical significance level. Then, it performed random permutations of the class labels. For each random permutation, all F-tests were re-computed for each peak. The class comparison tool computed the proportion of the random permutations that gave as many peaks significant at the selected level of significance as were found by comparing the true class labels. Protein and lipid profiles of the classes were considered different if this probability (designated as Permutation P value) was calculated $<0.05$.

To evaluate whether classes have different protein and lipid profiles, class prediction analyses were performed using all samples as a training set. The $0.632+$ bootstrap cross-validated misclassification rates was computed for all classifier functions (compound covariate predictor, diagonal linear discriminant analysis, 1- and 3-nearest neighbors, nearest centroid, and support vector machine) in the training set. Then, class labels were randomly shuffled and the cross-validated misclassification rate was computed for each random dataset. Permutation $P$ value, which is defined as the proportion of random datasets that give as small misclassification rate as is obtained with real class labels, was then calculated. MALDI MS profiles of the classes were considered different if this permutation $P$ value was $<0.05$.

To estimate the predictive power of discriminatory peaks, the class prediction analyses were also performed by randomly dividing the whole sample into two (training and test) subsets at 1-to-1 ratio. Randomization was performed using nQuery Advisor software (version 7.0, Statistical Solutions, Saugus, MA).

\section{Results}

MALDI MS analyses were performed for 34 pairs of retrospective surgical tissue samples (34 breast cancers and 34 adjacent normal tissue samples). Adjacent normal tissue samples were collected at least $2 \mathrm{~cm}$ apart from the cancer margin. Table 1 summarizes the clinico-pathological characteristics of analyzed tissue samples. There were 30 adenocarcinomas (luminal $(\mathrm{n}=18)$, HER2 $+(\mathrm{n}=7)$, and triple-negative $(\mathrm{n}=5))$, and 4 metaplastic carcinomas. In 16 out of 34 breast cancer samples (47.1\%), the entire sample had $>50 \%$ tumor content. In the remaining 18 samples (52.9\%), the pathologist marked the hematoxylin and eosin (H\&E) slide at the tumor-rich (> 50\% tumor content) area,

\section{Table 1 Clinico-pathological characteristics}

\begin{tabular}{|c|c|}
\hline \multicolumn{2}{|l|}{ Age, yr } \\
\hline Range & $33-73$ \\
\hline Median & 45 \\
\hline \multicolumn{2}{|l|}{ Gender } \\
\hline Female & $34(100 \%)$ \\
\hline \multicolumn{2}{|l|}{ AJCC Stage } \\
\hline IA & $6(17.6 \%)$ \\
\hline$\| \mathrm{A}$ & $16(47.1 \%)$ \\
\hline$\| B$ & $1(2.9 \%)$ \\
\hline$\| \mathrm{A}$ & $9(26.4 \%)$ \\
\hline$\| \mathrm{II}$ & $2(5.9 \%)$ \\
\hline \multicolumn{2}{|l|}{ Location of primary tumor } \\
\hline Unilateral & $34(100 \%)$ \\
\hline Right & $18(52.9 \%)$ \\
\hline Left & $16(47.1 \%)$ \\
\hline Bilateral & 0 \\
\hline \multicolumn{2}{|l|}{ Histologic classification } \\
\hline Adenocarcinoma & $30(88.2 \%)$ \\
\hline Ductal & $26(86.7 \%)$ \\
\hline Lobular & $1(3.3 \%)$ \\
\hline Mixed ductal and lobular & $1(3.3 \%)$ \\
\hline Mucinous & $2(6.6 \%)$ \\
\hline Metaplastic & $4(11.7 \%)$ \\
\hline \multicolumn{2}{|l|}{ Immunohistochemistry } \\
\hline \multicolumn{2}{|l|}{ Estrogen receptor (ER) } \\
\hline Positive & $24(70.6 \%)$ \\
\hline Negative & $10(29.4 \%)$ \\
\hline \multicolumn{2}{|l|}{ Progesterone receptor (PR) } \\
\hline Positive & $26(76.5 \%)$ \\
\hline Negative & $8(23.5 \%)$ \\
\hline \multicolumn{2}{|l|}{ HER2 } \\
\hline Positive & $14(41.2 \%)$ \\
\hline Negative & $20(58.8 \%)$ \\
\hline \multicolumn{2}{|l|}{ Ki67 } \\
\hline$<15 \%$ & $14(41.2 \%)$ \\
\hline$\geq 15 \%$ & $20(58.8 \%)$ \\
\hline \multicolumn{2}{|l|}{ Intrinsic subtype } \\
\hline Adenocarcinoma & $30(88.2 \%)$ \\
\hline Luminal (ER+ and/or PR+) & $18(60.0 \%)$ \\
\hline HER2 (HER2+ regardless of ER status) & $7(23.3 \%)$ \\
\hline Triple negative (ER-, PR-, and HER2-) & $5(16.7 \%)$ \\
\hline Metaplastic & $4(11.7 \%)$ \\
\hline
\end{tabular}

AJCC, American Joint Committee on Cancer ( $7^{\text {th }}$ Edition)

being careful to deposit the matrix within the boundary of the marked tumor-rich area (Additional File 1, Figure S1).

Mass spectra were acquired on individual spots for each tissue section, and these spectra were averaged together after pre-processing to create one average spectrum per patient. The average spectra were composed of 2 to 11 individual protein measurements for cancer samples (with a median value of 5), and 2 to 10 individual protein 
measurements for adjacent normal samples (with a median value of 5). The average spectra were composed of 3 to 8 individual lipid measurements (with a median value of 4) for both cancer and normal samples. It was possible that same tissue area was profiled multiple times (up to three spots) from different tissue sections loaded on different ITO slides. Individual measurements were averaged to minimize intra-sample variability. Post-spectral processing identified 85 protein and 144 lipid features (78 for the positive ion mode and 66 for the negative ion mode) across the entire mass range for all of the samples studied (Figure 1).

\section{Cancer versus adjacent normal breast tissue}

A principal component analysis (PCA) plot graphically demonstrated that cancer and adjacent normal samples were separately clustered in an unsupervised analysis (Figure 2A). When a class comparison analysis was performed using BRB-ArrayTools, the proportion of the random permutations that gave as many significant peaks at a feature selection of $P<10^{-5}$ as were found by comparing the true class labels (cancer $v s$ normal) was < 0.001, strongly suggesting that the cancer and normal tissue samples have significantly different protein and lipid profiles (Table 2). Class prediction analysis was subsequently performed after randomly dividing the entire set of samples into two groups at 1-to-1 ratio. At a feature selection $P<0.001$, the median class prediction accuracy in test sets was $94.1 \%$ for all classifiers tested, in 100 random training-to-test partitions. Thus, breast cancer and adjacent normal tissues have clearly different protein and lipid profiles.

To evaluate whether patients' age affects cancer-associated protein and lipid alteration, the cancer/normal peak area ratio was compared between older ( $\geq 50$ years, $\mathrm{n}=10)$ and younger $(<50$ years, $\mathrm{n}=24)$ age groups at feature selection $\mathrm{P}<0.05$, using class comparison algorithm of BRB-ArrayTools. The probability of getting as many significant peaks by chance as was obtained with real class labels, if there are no real differences between

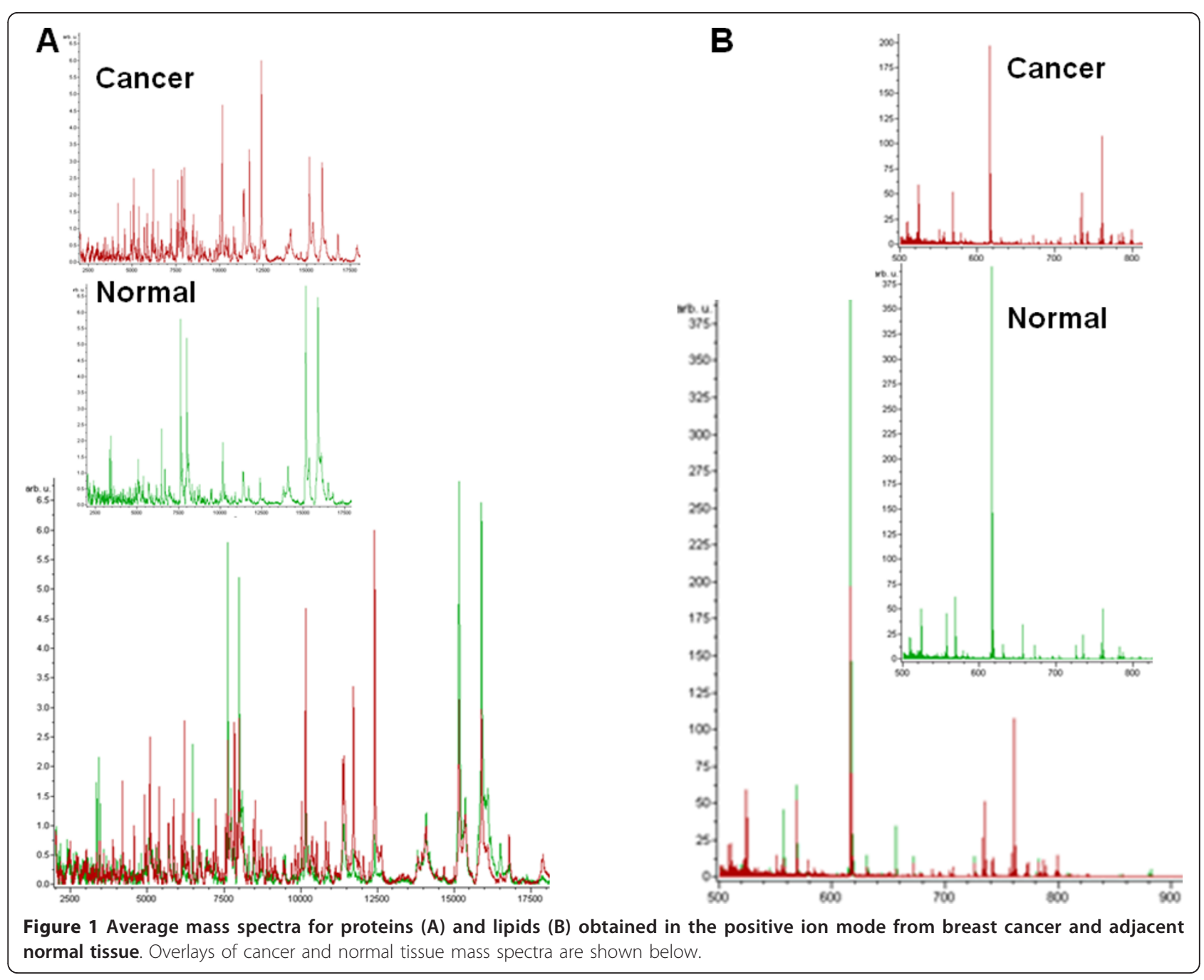



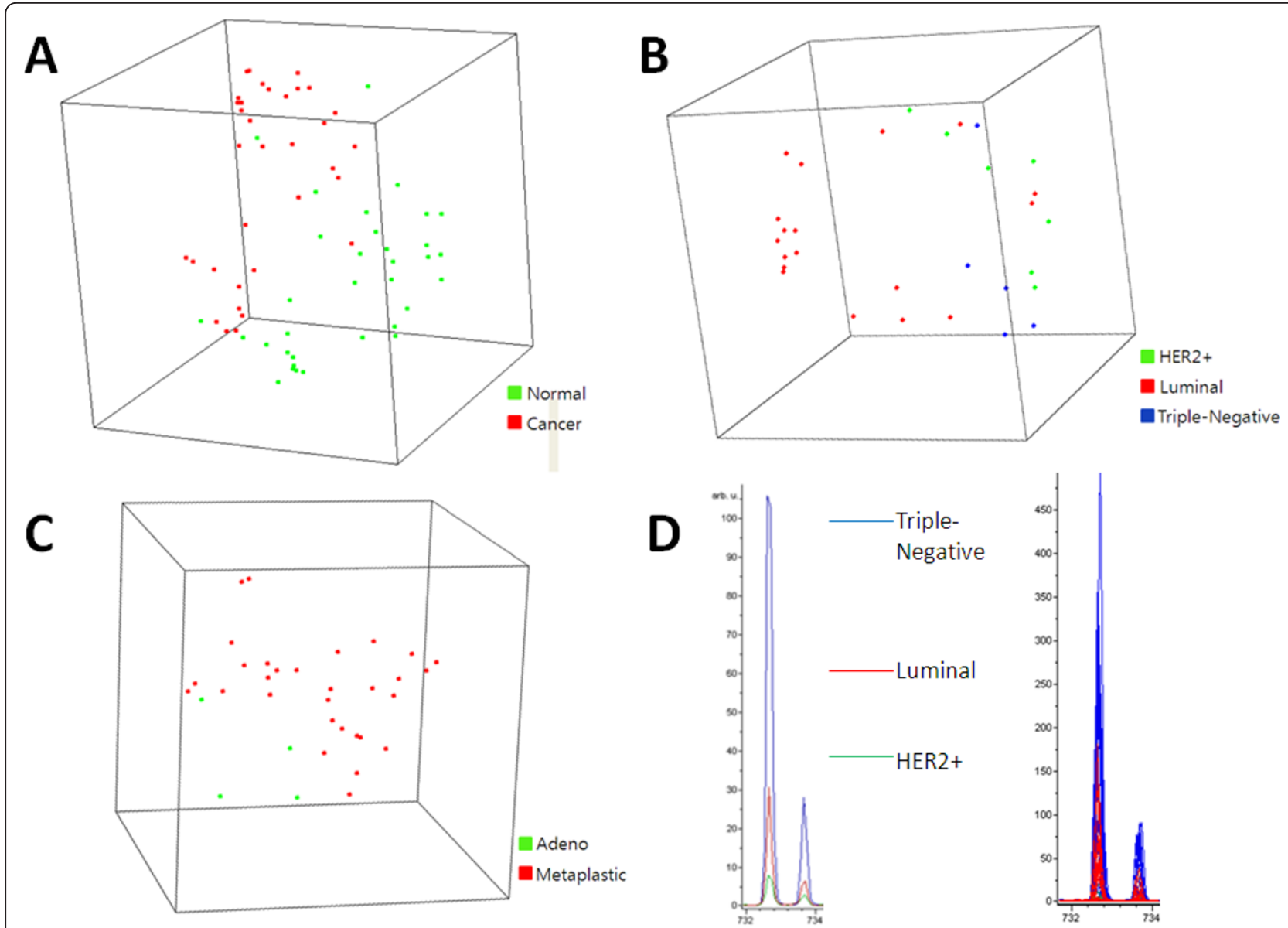

Figure 2 Principal component analysis and Intensity Profile. (A) A principal component analysis plot for 34 pairs of breast cancer (shown in red) and adjacent normal (shown in green) tissue samples, which graphically represents 1-correlation distances among samples. Each sphere represents a single sample, and samples whose protein expression profiles are very similar are shown close together. (B) A principal component analysis plot for luminal (shown in red), HER2+ (shown in green), and triple-negative breast adenocarcinoma samples (shown in blue) (C) A principal component analysis plot for metaplastic carcinomas (shown in green) and adenocarcinomas (shown in red). (D) Intensity profile for a representative lipid ( $\mathrm{m} / \mathrm{z}=732.58$ in the positive ion mode) differentially expressed among intrinsic subtypes. The average peak of the intrinsic subtype (left) and all single peaks (right) are shown.

class, was 0.78 , suggesting that cancer-associated protein and lipid alteration was not significantly different between older and younger age groups.

\section{Classification according to intrinsic subtype}

According to the PCA analysis, cancer samples were clustered according to their intrinsic subtypes (Figure 2B). Class comparison was performed between intrinsic subtypes that were defined by immunohistochemistry (luminal [ER+ and/or PR+] vs HER2 [HER2 +] vs triplenegative [ER-, PR-, and HER2-]. At a feature selection $P<0.001,19$ peaks were significantly different among subtypes (Table 3 ). The probability of getting at least 19 peaks significantly by chance (at the 0.001 level) with no real differences between the classes was 0.002 . For class prediction analysis, all 30 cancer samples were first used as a training set. At a feature selection $P<0.001$, permutation $P$ values for $0.632+$ bootstrap cross-validated misclassification rates were $<0.01$ for all classifiers tested. These results indicate that breast tumor intrinsic types have different protein and lipid profiles. When these analyses were performed separately in protein and lipid datasets, lipid profiles demonstrated consistently lower permutation $P$ values for cross-validated misclassification rate, across feature selection $P$ values ranging 0.001 to 0.05 (data not shown).

We then planned to estimate the predictive power of discriminatory proteins and lipids in training-to-test partitions, although this analysis is limited by the sample size. At a feature selection $P<0.05$, the median prediction accuracy in test sets ranged from $80 \%$ to $81.3 \%$ (80\%, $81.3 \%, 80 \%$, and $80 \%$, for diagonal linear discriminant analysis, 1-nearest neighbor, 3-nearest neighbors, and nearest centroid, respectively), in 100 random 
Table 2 Peaks differentially expressed between cancer and adjacent normal tissue samples at a feature selection $P<$ $10^{-5}$

\begin{tabular}{|c|c|c|c|c|c|c|}
\hline \multicolumn{4}{|c|}{ Overexpressed in cancer } & \multicolumn{3}{|c|}{ Underexpressed in cancer } \\
\hline $\mathrm{m} / \mathrm{z}$ & $\mathrm{P}$ & Ratio $^{1}$ & Assignment & $\mathrm{m} / \mathrm{z}$ & $\mathrm{p}$ & Ratio $^{1}$ \\
\hline 6206.58 & $1.00 \mathrm{E}-07$ & 1.6 & & 5150.41 & $3.50 \mathrm{E}-06$ & 0.9 \\
\hline 7222.53 & $1.00 \mathrm{E}-06$ & 1.4 & & 7618.64 & $<1 \mathrm{E}-10$ & 0.6 \\
\hline 8514.66 & 1.10E-06 & 1.4 & & 9486.03 & 1.00E-07 & 0.7 \\
\hline 11719.24 & $<1 \mathrm{E}-07$ & 1.8 & & 16089.36 & $9.90 \mathrm{E}-06$ & 0.6 \\
\hline \multirow[t]{2}{*}{12411.2} & $<1 \mathrm{E}-07$ & 2.1 & & & & \\
\hline & & & & n545.56 & 2.70E-06 & 0.5 \\
\hline p734.58 & $3.60 \mathrm{E}-06$ & 2.0 & $P C\{32: 0\}[M+H]^{+}$ & n554.49 & 4.00E-07 & 0.4 \\
\hline p741.62 & $<1 \mathrm{E}-07$ & 2.1 & $\mathrm{SM}\{\mathrm{d} 18: 1 / 16: 0\}[\mathrm{M}+\mathrm{K}]^{+}$ & n568.56 & 9.60E-06 & 0.5 \\
\hline p760.62 & 2.90E-06 & 2.0 & $P C\{34: 1\}[M+H]^{+}$ & n574.61 & 5.70E-06 & 0.7 \\
\hline p772.58 & $<1 \mathrm{E}-07$ & 1.8 & $P C\{32: 0\}[M+K]^{+}$ & n594.5 & $1.00 \mathrm{E}-07$ & 0.6 \\
\hline \multirow[t]{2}{*}{ p798.58 } & $<1 \mathrm{E}-08$ & 2.1 & $\mathrm{PC}\{34: 1\}[\mathrm{M}+\mathrm{K}]^{+}$ & n609.74 & 1.90E-06 & 0.4 \\
\hline & & & & n651.64 & $3.40 \mathrm{E}-06$ & 0.5 \\
\hline n505.37 & $<1 \mathrm{E}-09$ & 5.3 & & n666.79 & 7.00E-07 & 0.5 \\
\hline \multirow[t]{5}{*}{ n605.64 } & $<1 \mathrm{E}-10$ & 5.3 & & n679.13 & $6.40 \mathrm{E}-06$ & 0.5 \\
\hline & & & & n878.89 & $2.50 \mathrm{E}-06$ & 0.6 \\
\hline & & & & n907.09 & 7.50E-06 & 0.5 \\
\hline & & & & n917.48 & $3.60 \mathrm{E}-06$ & 0.5 \\
\hline & & & & n997.7 & 1.80E-06 & 0.5 \\
\hline
\end{tabular}

${ }^{1}$ Ratio, cancer/normal

$\mathrm{p}$, lipids identified in the positive ion mode

$\mathrm{n}$, lipids identified in the negative ion mode

SM, Sphingomyelin

training-to-test partitions. Discriminatory peaks are listed in Table 3.

\section{Metaplastic carcinoma vs adenocarcinoma}

Metaplastic carcinoma is a unique breast cancer subtype, characterized by distinct morphologic feature and poor prognosis [23]. To further evaluate whether protein and lipid profiles could distinguish biological feature, we compared metaplastic carcinomas $(n=4)$ with adenocarcinomas $(n=30)$ for protein and lipid profiles. According to PCA analysis, metaplastic carcinomas were clearly separated from adenocarcinomas (Figure $2 \mathrm{C}$ ). For class prediction analysis, all 34 cancer samples were used as a training set, given the small number of metaplastic carcinomas. At a feature selection $P<0.001$, permutation $P$ values for $0.632+$ bootstrap cross-validated misclassification rates were $<0.05$ for all classifiers tested $(0.01,<0.01,<0.01$, $<0.01,0.01$, and $<0.01$, for the compound covariate predictor, diagonal linear discriminant analysis, 1-nearest neighbor, 3-nearest neighbors, nearest centroid, and support vector machine, respectively). Although sample size is small, metaplastic carcinomas appear to have unique protein and lipid profiles.

\section{Discussion}

This study demonstrates that histology-directed MALDI MS analysis of lipids and proteins may differentiate between cancerous and normal epithelium and among intrinsic subtypes of breast cancer. Phosphatidylcholines (PCs) $\{34: 1\}\left(\mathrm{m} / \mathrm{z}=760.62[\mathrm{M}-\mathrm{H}]^{+}\right.$and $\left.798.58\left[\mathrm{M}-\mathrm{K}^{+}\right]\right)$ were found to be overexpressed in breast cancer. In our previous publication [24], we demonstrated that cholangiocarcinomas and pancreatic cancers have increased PC $\{34: 1\}(\mathrm{m} / \mathrm{z}=760)$. We also validated the identity of the $\mathrm{PC}\{34: 1\}$ peak by comparing MS/MS spectra of $[\mathrm{M}+\mathrm{H}]^{+}$ ion $(\mathrm{m} / \mathrm{z} 760)$ of $34: 1-\mathrm{PC}$ species found on a cholangiocarcinoma sample with those of standard 18:1/16:0-PC species [24]. This peak was also increased in our ovarian cancer tissue samples as compared with adjacent normal tissue (manuscript in preparation). Membrane phospholipid composition influences the activity of membraneassociated phospholipase A2 (PLA2) [25], which plays a role in carcinogenesis [26], and that overexpression of ChoK $\alpha 1$, which generates $\mathrm{PC}$, is oncogenic [27].

More importantly, we have found that luminal, HER2+, and triple-negative breast cancer subtypes have different protein and lipid MALDI MS profiles. This result is consistent with a previous report that protein MALDI imaging MS classifies breast cancer tissue specimens according to HER2 status [13]. Using similar tissue MALDI MS technology, we confirmed and extended previous reports by identifying the intrinsic subtype-specific protein and lipid profiles. Brozkova, et al. also reported that SELDI-TOF MS could classify breast cancer tissue 
Table 3 Peaks differentially expressed among intrinsic subtypes at a feature selection $P<0.001$

\begin{tabular}{|c|c|c|c|c|c|}
\hline \multirow[t]{2}{*}{$\mathrm{mz}$} & \multirow[t]{2}{*}{$p$} & \multicolumn{3}{|c|}{ Relative peak intensity } & \multirow[t]{2}{*}{ Assignment } \\
\hline & & Luminal & HER2+ & Triple-negative & \\
\hline p514.32 & 0.0006 & 2.2 & 3.8 & 2.0 & \\
\hline p515.2 & 0.0007 & 1.7 & 2.8 & 1.3 & \\
\hline p531.34 & 0.0002 & 1.3 & 2.4 & 1.1 & \\
\hline p534.25 & 0.0001 & 1.8 & 3.0 & 1.5 & $P C\{16: 1\}[M+H]^{+}$ \\
\hline p535.22 & 0.0001 & 1.2 & 1.7 & 1.1 & \\
\hline p578.67 & 0.0000 & 14.6 & 5.3 & 3.1 & \\
\hline p644.33 & 0.0004 & 3.6 & 2.1 & 1.5 & \\
\hline p678.32 & 0.0006 & 4.8 & 4.6 & 2.6 & \\
\hline p706.52 & 0.0003 & 2.4 & 2.7 & 5.7 & $P C\{30: 0\}[M+H]^{+}$ \\
\hline p732.58 & $<0.001$ & 1.3 & 2.7 & 11.0 & $P C\{32: 1\}[\mathrm{M}+\mathrm{H}]^{+}$ \\
\hline n505.37 & 0.0001 & 13.2 & 90.5 & 78.1 & \\
\hline n527.44 & 0.0005 & 4.5 & 1.6 & 1.6 & \\
\hline n545.56 & $<0.001$ & 5.0 & 1.5 & 1.7 & \\
\hline n552.56 & 0.0003 & 2.3 & 1.1 & 1.1 & \\
\hline n554.49 & $<0.001$ & 3.8 & 1.2 & 1.2 & \\
\hline n587.67 & 0.0009 & 4.3 & 1.6 & 1.7 & \\
\hline n589.59 & 0.0002 & 3.6 & 1.4 & 1.4 & \\
\hline n627.71 & 0.0008 & 4.7 & 1.9 & 2.1 & \\
\hline n631.89 & 0.0005 & 2.5 & 1.3 & 1.2 & \\
\hline
\end{tabular}

${ }^{1}$ Ratio, cancer/normal

$\mathrm{p}$, lipids identified in the positive ion mode

$\mathrm{n}$, lipids identified in the negative ion mode

lysates to five groups which were analogous to intrinsic subtypes [28]. Thus, our MALDI profiles contain information about histopathological and biological feature of this heterogeneous disease [29]. Molecular profiles we identified are consistent with previous data generated via different analysis platforms. We have found that triplenegative breast cancers overexpress $\mathrm{PC}\{32: 1\}[\mathrm{M}+\mathrm{H}]^{+}$ $(\mathrm{m} / \mathrm{z}=732.58)$ and $\mathrm{PC}\{30: 0\}[\mathrm{M}+\mathrm{H}]^{+}(\mathrm{m} / \mathrm{z}=706.5)$, compared with luminal and HER2 subtypes. According to a recent report by Hilvo et al., these lipids are underexpressed in ER-positive breast cancer tissue samples, compared with ER-negative samples $(P=0.001$ and $P<$ 0.001 , respectively) [16]. In our data, these lipids were also positively correlated with ER negativity $(P=0.029$ and 0.002 , respectively).

Notably, our relatively simple approach takes less analytic time and tissue amount than lysate-based proteomics technologies used by aforementioned studies $[16,29]$, which provides a clear advantage as a possible diagnostic aid, once our discriminatory profiles are validated in a larger dataset. Our novel two-matrix (SA and DHB/CHCA) MALDI profiling offers additional layer of molecular information, and, therefore, may possibly capture biological features of the breast cancer better than one-matrix MALDI profiling. Conversely, our relatively simple approach needs to be improved for obtaining tumor cell-specific mass spectra to better profile complex clinical material such as the needle biopsy of breast cancers, by using MALDI imaging MS [13] or a robotic spotter that deposits micron-sized droplets of matrix [12]. Also, our study is limited by incomplete assignment of discriminatory peaks using MS/MS, and by the sample size which is sufficient for statistical significance yet relatively small. Further studies on a larger scale are clearly warranted to validate discriminatory protein and lipid profiles identified by this proof-of-concept study.

\section{Conclusions}

Luminal, HER2+, and triple-negative breast cancer subtypes have different protein and lipid MALDI MS profiles. Protein and lipid profiles identified by our novel two-matrix (SA and DHB/CHCA) MALDI analyses are sensitive and may capture biological features of the breast cancer.

\section{Additional material}

Additional file 1: Procedures for MALDI MS analysis. A representative cancer tissue cryosection, with the DHB/CHCA matrix applied at the locations marked in the H\&E section, is shown at the bottom. The H\&E section marked at discrete locations (enriched in tumor cells) using a red color marker pen (center) and magnified $(\times 20)$ areas of the H\&E-stained section corresponding to matrix-loaded spots (top left and right) are shown at the top. 


\section{Acknowledgements}

The work was supported by Converging Research Center Program through the Ministry of Education, Science and Technology of Korea (2010K001121) and by National Cancer Center Grant 0910570. The authors thank Dr. Byoung Ho Nam for his help with statistical analyses.

\section{Author details}

${ }^{1}$ National Cancer Center, Goyang, 410-769, Korea. ${ }^{2}$ Division of Mass Spectrometry Research, Korea Basic Science Institute, Ochang, 363-883, Korea. ${ }^{3}$ Center for Nano-Bio Convergence, Korea Research Institute of Standards and Science, Daejeon, 305-340, Korea. ${ }^{4}$ Department of Molecular Biotechnology, WCU Program, Konkuk University, Seoul, 143-701, Korea. ${ }^{5}$ Department of Biological Sciences, Sungkyunkwan University, Suwon, 440746, Korea. ${ }^{6}$ Graduate School of Analytical Science and Technology, Chungnam National University, Daejeon, 305-764, Korea.

\section{Authors' contributions}

HSK designed experiments and collected samples; SCL processed tissue and performed MALDI MS; YSP performed MSMS; YEJ performed MALDI MS; JHL performed MALDI MS; SYJ collected samples; IHP collected samples; SHJ collected samples; HMP analyzed clinical data; CWY performed histopathological review; SHP reviewed manuscript; SYH performed MALDI MS; KPK performed MALDI MS; WHK performed MSMS; JSR designed experiments, performed clinical annotation, and contributed to the writing of the manuscript. HKK designed experiments and analyzed the data. All authors read and approved the final manuscript.

\section{Competing interests}

The authors declare that they have no competing interests.

Received: 15 April 2011 Accepted: 27 October 2011

Published: 27 October 2011

\section{References}

1. Cho WC: Contribution of oncoproteomics to cancer biomarker discovery. Mol Cancer 2007, 6:25.

2. Cho WC: Proteomics technologies and challenges. Genomics Proteomics Bioinformatics 2007, 5(2):77-85.

3. Huang HL, Stasyk T, Morandell S, Dieplinger H, Falkensammer G, Griesmacher A, Mogg M, Schreiber M, Feuerstein I, Huck CW, Stecher G, Bonn GK, Huber LA: Biomarker discovery in breast cancer serum using 2D differential gel electrophoresis/MALDI-TOF/TOF and data validation by routine clinical assays. Electrophoresis 2006, 27(8):1641-1650.

4. Drake RR, Cazares LH, Jones EE, Fuller TW, Semmes OJ, Laronga C: Challenges to developing proteomic-based breast cancer diagnostics. OMICS 2011, 15(5):251-259.

5. Hamrita B, Nasr HB, Chahed K, Chouchane L: Proteomics approaches: New Technologies and Clinical Applications in Breast Carcinomas. Gulf $\rfloor$ Oncolog 2011, 1(9):36-44

6. Caprioli RM, Farmer TB, Gile J: Molecular imaging of biological samples: Localization of peptides and proteins using MALDI-TOF MS. Anal Chem 1997, 69:4751-4760.

7. Stoeckli M, Chaurand P, Hallahan DE, Caprioli RM: Imaging mass spectrometry: A new technology for the analysis of protein expression in mammalian tissues. Nature Med 2001, 7:493-496.

8. Yanagisawa K, Shyr Y, Xu BJ, Massion PP, Larsen PH, White BC, Roberts JR, Edgerton M, Gonzalez A, Nadaf S, Moore JH, Caprioli RM, Carbone DP: Proteomic patterns of tumour subsets in non-small-cell lung cancer. Lancet 2003, 362(9382):433-449.

9. Schwartz SA, Weil RJ, Thompson RC, Shyr Y, Moore JH, Toms SA, Johnson MD, Caprioli RM: Proteomic-based prognosis of brain tumor patients using direct-tissue matrix-assisted laser desorption ionization mass spectrometry. Cancer Res 2005, 65(17):7674-7681.

10. Kim HK, Reyzer ML, Choi IJ, Kim CG, Kim HS, Oshima A, Chertov O, Colantonio S, Fisher RJ, Allen JL, Caprioli RM, Green JE: Gastric cancerspecific protein profile identified using endoscopic biopsy samples via MALDI mass spectrometry. J Proteome Res 2010, 9(8):4123-4130.

11. Taguchi F, Solomon B, Gregorc V, Roder H, Gray R, Kasahara K, Nishio M, Brahmer J, Spreafico A, Ludovini V, Massion PP, Dziadziuszko R, Schiller J. Grigorieva J, Tsypin M, Hunsucker SW, Caprioli R, Duncan MW, Hirsch FR, Bunn PA Jr, Carbone DP: Mass spectrometry to classify non-small-cell lung cancer patients for clinical outcome after treatment with epidermal growth factor receptor tyrosine kinase inhibitors: a multicohort crossinstitutional study. J Natl Cancer Inst 2007, 99(11):838-46.

12. Cornett DS, Mobley JA, Dias EC, Andersson M, Arteaga CL, Sanders ME, Caprioli RM: A novel histology-directed strategy for MALDI-MS tissue profiling that improves throughput and cellular specificity in human breast cancer. Mol Cell Proteomics 2006, 5:1975-1983.

13. Rauser S, Marquardt C, Balluff B, Deininger SO, Albers C, Belau E, Hartmer R, Suckau D, Specht K, Ebert MP, Schmitt M, Aubele M, Höfler H, Walch A: Classification of HER2 receptor status in breast cancer tissues by MALDI imaging mass spectrometry. J Proteome Res 2010, 9(4):1854-1863.

14. Bougnoux P, Chajes V, Lanson M, Hacene K, Body G, Couet C, Le Floch O: Prognostic significance of tumor phosphatidylcholine stearic acid level in breast carcinoma. Breast Cancer Res Treat 1992, 20(3):185-194.

15. Moestue SA, Borgan E, Huuse EM, Lindholm EM, Sitter B, Børresen-Dale AL, Engebraaten O, Maelandsmo GM, Gribbestad IS: Distinct choline metabolic profiles are associated with differences in gene expression for basal-like and luminal-like breast cancer xenograft models. BMC Cancer 2010, 10:433.

16. Hilvo M, Denkert C, Lehtinen L, Muller B, Brockmoller S, Seppanen-Laakso T, Budczies J, Bucher E, Yetukuri L, Castillo S, Berg E, Nygren H, Sysi-Aho M, Griffin JL, Fiehn O, Loibl S, Richter-Ehrenstein C, Radke C, Hyotylainen T, Kallioniemi O, Iljin K, Oresic M: Novel theranostic opportunities offered by characterization of altered membrane lipid metabolism in breast cancer progression. Cancer Res 2011, 71:3236-3245.

17. GLOBOCAN 2008 (IARC): Section of Cancer Information (13/4/2011)

18. Jackson SN, Woods AS: Direct profiling of tissue lipids by MALDITOFMS. J Chromatogr B Analyt Technol Biomed Life Sci 2009, 877(26):2822-2829.

19. Shanta SR, Zhou LH, Park YS, Kim YH, Kim Y, Kim KP: Binary matrix for MALDI imaging mass spectrometry of phospholipids in both ion modes. Anal Chem 2011, 83(4):1252-1259.

20. Cheang MC, Voduc D, Bajdik C, Leung S, McKinney S, Chia SK, Perou CM, Nielsen TO: Basal-like breast cancer defined by five biomarkers has superior prognostic value than triple-negative phenotype. Clin Cancer Res 2008, 14:1368-1376.

21. Nielsen TO, Hsu FD, Jensen K, Cheang M, Karaca G, Hu Z, HernandezBoussard T, Livasy C, Cowan D, Dressler L, Akslen LA, Ragaz J, Gown AM, Gilks CB, van de Rijn M, Perou CM: Immunohistochemical and clinical characterization of the basal-like subtype of invasive breast carcinoma. Clin Cancer Res 2004, 10:5367-5374.

22. Simon R, Lam A, Li MC, Ngan M, Menenzes S, Zhao Y: Analysis of gene expression data using BRB-Array Tools. Cancer Informatics 2007, 2:11-17.

23. Jung $S Y, K i m ~ H Y, N a m B H$, Min SY, Lee SJ, Park C, Kwon Y, Kim EA, Ko KL, Shin KH, Lee KS, Park IH, Lee S, Kim SW, Kang HS, Ro J: Worse prognosis of metaplastic breast cancer patients than other patients with triplenegative breast cancer. Breast Cancer Res Treat 2010, 120(3):627-637.

24. Park YS, Yoo CW, Lee SC, Park SJ, Oh JH, Yoo BC, Paik SS, Lee KG, Jin SY, Kim SC, Kim KP, Kim YH, Choi DH, Kim HK: Lipid profiles for intrahepatic cholangiocarcinoma identified using matrix-assisted laser desorption/ ionization mass spectrometry. Clin Chim Acta 2011, 412(2122):1978-1982.

25. Momchilova A, Markovska T, Pankov R: Phospholipid dependence of membrane-bound phospholipase A2 in ras-transformed NIH 3T3 fibroblasts. Biochimie 1998, 80(12):1055-1062.

26. Momchilova AB, Petkova DH, Koumanov KS: Phospholipid composition modifications influence phospholipase A2 activity in rat liver plasma membranes. Int J Biochem 1986, 18:945-952.

27. Gallego-Ortega D, Ramirez de Molina A, Ramos MA, Valdes-Mora F, Barderas MG, Sarmentero-Estrada J, Lacal JC: Differential role of human choline kinase alpha and beta enzymes in lipid metabolism: implications in cancer onset and treatment. PLoS One 2009, 4(11):e7819-7829.

28. Brozkova K, Budinska E, Bouchal P, Hernychova L, Knoflickova D, Valik D, Vyzula R, Vojtesek B, Nenutil R: Surface-enhanced laser desorption/ ionization time-of-flight proteomic profiling of breast carcinomas identifies clinicopathologically relevant groups of patients similar to previously defined clusters from cDNA expression. Breast Cancer Res 2008, 10(3):R48.

29. Perou CM, Sørlie T, Eisen MB, van de Rijn M, Jeffrey SS, Rees CA, Pollack JR, Ross DT, Johnsen H, Akslen LA, Fluge O, Pergamenschikov A, Williams C, 
Zhu SX, Lønning PE, Børresen-Dale AL, Brown PO, Botstein D: Molecular portraits of human breast tumours. Nature 2000, 406(6797):747-752.

Pre-publication history

The pre-publication history for this paper can be accessed here:

http://www.biomedcentral.com/1471-2407/11/465/prepub

doi:10.1186/1471-2407-11-465

Cite this article as: Kang et al:: Protein and lipid MALDI profiles classify

breast cancers according to the intrinsic subtype. BMC Cancer 2011

11:465.

Submit your next manuscript to BioMed Central and take full advantage of:

- Convenient online submission

- Thorough peer review

- No space constraints or color figure charges

- Immediate publication on acceptance

- Inclusion in PubMed, CAS, Scopus and Google Scholar

- Research which is freely available for redistribution

Submit your manuscript at 